\title{
La raza y el racismo en la república imposible de Rafael Serra
}

\author{
OSCAR MONTERO \\ City University of New York \\ Lehman College
}

\section{RESUMEN}

Rafael Serra, autodidacta, tabaquero, y periodista, compartió con José Martí el exilio en New York, donde con el apoyo del Maestro, fundó La Liga, centro docente y cultural, cuyo propósito principal era la educación de «hombres de color» cubanos y puertorriqueños. El tema central de la labor periodística de Serra, su misión más bien, fue la defensa de los derechos civiles, ignorados y constantemente amenazados, de los cubanos de origen africano. Montero analiza algunos textos de Serra para considerar su incapacidad para captar las contradicciones culturales entre la lucha necesaria contra el racismo y su identificación con las ideas centrales de la llamada civilización occidental. El propósito del trabajo es indagar en algunos de los textos de Serra sobre estas contradicciones, con el ánimo no solo de repasar lo consabido sobre el antirracismo de Serra, sino de actualizarlo, es decir, vincularlo a nuestros propios racismos, para sugerir tal vez las formas en que podrían combatirse hoy día.

Palabras clave: Rafael Serra, Cuba, derechos civiles, racismo, raza.

\section{ABSTRACT}

Rafael Serra was a self-educated tobacco worker and journalist, exiled in New York City alongside José Martí. In New York, with the support of Martí, Serra founded La Liga, an educational and cultural institution whose goal was to educate Cuban and Puerto Rican «people of color.» The central topic of Serra's reporting was the defense of civil rights, ignored and constantly threatened, of Cubans of African descent. Montero analyzes several of Serra's texts to consider his apparent inability to perceive the cultural contradictions between the necessary struggle against racism and his identification with the central tenets of so-called Western civilization. The goal of this article is to study some of Serra's texts, where these contradictions are evident. The article reviews what is what is well-known about Serra's antiracism, but also aims to update it, that is, to connect it to present day racism(s), and suggest ways in which they may be confronted.

Keywords: Rafael Serra, Cuba, Civil Rights, Racism, Race.

Es conocido el papel destacado de Rafael Serra en el ámbito de José Martí. Serra, tabaquero autodidacta, compartió con Martí el exilio en New York, donde con el apoyo del Maestro, fundó La Liga, centro docente y cultural, cuyo propósito principal era la educación de «hombres de color» cubanos y puertorriqueños (González Veranés 19). El tema central de la labor periodística de Serra, su misión más bien, fue la defensa de los derechos civiles, ignorados y constantemente amenazados, de los cubanos de origen africano ${ }^{1}$.
Oscar Montero

Cubano residente en Nueva York, Oscar Montero es investigador independiente, traductor y escritor. Es autor de Erotismo y representación en Julián del Casal y José Martí. An Introduction, además de traductor del libro de Sylvia Molloy Signs of Borges. Su obra de teatro Las rutas de Julia de Burgos fue interpretado por la compañia del International Theater Arts Institute en Lehman Stages, Nueva York, en febrero del 2014. Ha sido profesor de Lehman College, The Graduate Center, City University of New York, y profesor invitado de Columbia University, Princeton, y State University of New York, Stony Brook.
1 He tomado estos datos y otros a lo largo de este trabajo del libro pionero de Deschamps Chapeaux, Rafael Serra y Montalvo, obrero incansable de nuestra independencia (1975).

La raza y el racismo en la república imposible de Rafael Serra 


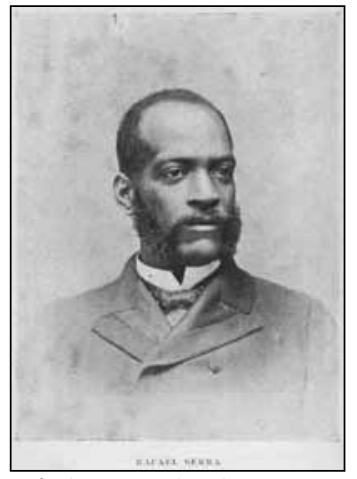

Rafael Serra. Schomburg Center for Research in Black Culture. The New York Public Library Digital Collections. 1896.

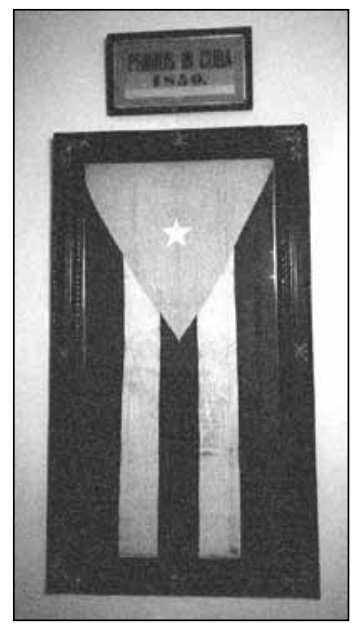

Primera Bandera Cubana. Mu seo de la Ciudad de La Habana. Fotografía de José Gomariz.

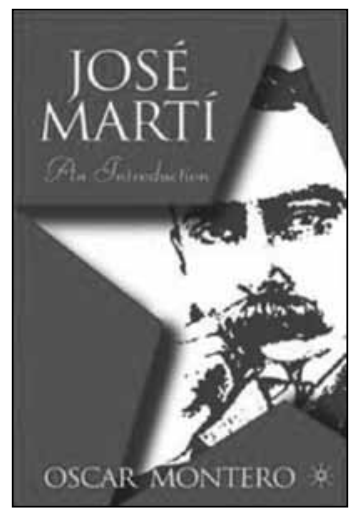

2 Todas las traducciones son mías. 3 En las citas de la obra de Serra, conservo la puntuación y la ortografía originales, excepto en caso de errores de imprenta obvios, que he corregido para evitar el uso extenso de «sic».

La raza y el racismo en la república imposible de Rafael Serra

OSCAR MONTERO
Sin embargo, si estos datos sobre Serra se han divulgado en los últimos años, hay una parte importante de su obra que creo que no se ha profundizado lo suficiente. Me refiero a la ausencia en Serra, en la expresión justa de Aline Helg, de un «contradiscurso» que al menos sentara las bases para el desarrollo posterior de lo que hoy llamaríamos una identidad propia. En las páginas que siguen me detendré en algunos textos de Serra para considerar la incapacidad de Serra para captar las contradicciones entre la lucha necesaria contra el racismo y su identificación con las ideas centrales de la llamada civilización occidental (Helg 136). Mi propósito entonces, desde comienzos de este otro siglo y consciente de las distorsiones que traigo a mi labor, es detenerme en algunos de los textos de Serra sobre estas contradicciones, con el ánimo no solo de repasar lo consabido sobre el antirracismo de Serra sino de actualizarlo, es decir, vincularlo a nuestros propios racismos, tan variopintos y tan persistentes, para sugerir tal vez las formas en que podrían combatirse hoy día.

Creo que el comentario de Helg no es ni anacrónico ni injusto, y de hecho la historiadora lo respalda con evidencia del «orgullo en sus raíces africanas» de diversas organizaciones muy activas en los primeros años de la república (Helg 132)2. Es consabido, y no se trata de argüir lo contrario, que las estrategias de Serra y sus intereses personales no coincidían con los orígenes de un orgullo afrocéntrico. Sin embargo, no se trata solo de un rechazo evidente de esas manifestaciones culturales sino de la insistencia de Serra en la superioridad de las instituciones y los valores asociados con la gente de origen europeo, o como él mismo los llama, «los blancos». Creo que en la divulgación de un Serra martiano, luchador por la igualdad de todos, méritos que en lo absoluto se trata de cuestionar, no se ha comentado el racismo casi inconsciente de algunas de las ideas principales de su perfil intelectual.

Después de una estadía en Cayo Hueso en 1884, Serra se trasladó con su familia a Nueva York, donde permaneció hasta su regreso a la patria en 1899. Después de la muerte de Martí, Serra publicó en Nueva York (18961898) y luego en La Habana (1899-1901) el periódico La Doctrina de Martí, que afirmó sobre todo la independencia radical de Cuba, amenazada por anexionistas, autonomistas y una vez establecida la república neocolonial por la falta de unión y cooperación entre los diversos partidos. En 1904 fue elegido a la Cámara de Representantes por la provincia de Oriente, como miembro del Partido Nacional, y continuó su labor periodística. En ensayos diversos y en su obra poética, Serra no deja de señalar las injusticias del racismo $\mathrm{y}$ de vincular dichas injusticias a la lucha por la independencia de Cuba. Habría que añadir que el ahínco con que Serra insiste en ese vínculo se convierte en el rasgo distintivo de su ideario. En los artículos publicados en la prensa y luego incluidos en sus libros, Serra considera que el racismo no se puede entender solamente como la manifestación de la maldad innata de algunos individuos, de su egoísmo y falta de compasión sino que es síntoma de un sistema social, capaz de ser alterado por, en los términos que suele emplear, «hombres de bien», cualquiera que sea el color de su piel.

Los comentarios más claros y más poderosos de Serra subrayan la necesidad de cambiar todo sistema político y la sociedad que lo acoja que no garanticen la igualdad y la justicia para todos los ciudadanos. En un artículo titulado "Hay que pensar», publicado en $L a$ Doctrina de Martí y luego en Ensayos politicos (1899) dice: «Revolucionar es remover, destruir y cambiar de una vez un sistema por otro que en nada se parezca al sistema caído. Cuando á un sistema solo se le quita ó añade, quedando siempre su base original, entonces no se revoluciona sino se evoluciona: y los cubanos, como principio de salvación y de progreso, tenemos que revolucionar» $(43)^{3}$.

En otras palabras, una vez derrotado el sistema colonial perdura el lastre odioso de la esclavitud, evidente en la marginación y en las injusticias cometidas contra la población de origen africano, mas la situación puede y tiene que cambiar. A pesar de esta expresión casi militante sobre la necesidad de "revolucionar», Serra afirma una y otra vez la preferencia por una solución pacífica llevada a cabo por individuos de buena voluntad, cualquiera que sea su «clase», categoría con la cual Serra tiende a fundir la categoría de «raza». En un artículo publicado en plena guerra, enero 30 de 1896, y reproducido en Ensayos políticos, Serra insiste en que frente a la intransigencia de los españoles el único remedio es «la razón del machete» (123), pero jamás justificará esa «razón del machete» cuando se trate de luchar contra el racismo de los mismos cubanos. 
En los ensayos y notas incluidos en $\mathrm{La}$ república posible, publicado póstumamente en 1909, Serra reitera de manera más explícita la relación evidente entre las diferencias de clase, producto de sistemas de explotación, y diferencias «étnicas» propias de Cuba. Los dos grandes problemas de Cuba, dice Serra en uno de sus comentarios más conocidos, son «la cuestión económica y la del equilibrio armónico que debe existir entre los distintos elementos étnicos del país» (4). En 1909 Serra sigue firme en su idea de obtener ese «equilibrio armónico», martiano en su origen, entre todos los individuos de una nación. El uso de la expresión «elementos étnicos», en lugar de referirse a «diferencias raciales» o diferencias entre «hombres blancos y hombres negros», como dice en otros textos, sitúa el discurso antirracista de Serra en un plano más abstracto, más científico si se quiere, del todo acorde con su insistencia en el poder de la igualdad como idea capaz de lograr el deseado equilibrio entre todos. En los Ensayos políticos de 1899, en un artículo titulado «Educación y dinero», Serra afirma que de hecho ha tratado de evitar las categorías raciales, «blancos y negros», heredadas del colonialismo, pero que las utiliza con el fin de convencer a sus lectores:

nada ha de sorprender que para puntualizar ahora nuestras apreciaciones tengamos por un momento que hablar de blancos y negros. Pues la ausencia de este distingo en todo el contenido de este libro, es una prueba de que nos hemos desceñido el hábito colonial, y que si ahora prescindimos es en obsequio de la persuasión á que queremos conducir a nuestros benévolos lectores. (172)

En otras palabras, el racismo en Cuba es en gran medida el legado del colonialismo y en vez de insistir en las diferencias raciales, marcadas por el racismo cualquiera que sea su propósito, mejor trabajar, cuando sea posible, en «la ausencia de este distingo». Sin embargo, en 1907 Serra publica Para blancos y negros. Ensayos políticos, sociales y económicos, título que afirma que en la república es necesario el uso de «este distingo». El uso de estos términos, de manera prominente en el título de su libro, sugiere que Serra contempla la opción de identidades diferentes, sin que esas diferencias resten valor a cualquiera de dichas identidades. El uso en el título de «blancos y

negros» en 1907 marca la distancia que ha sido capaz de tomar Serra frente a la prédica martiana de igualdad universal.

Pero afirmar la diferencia, por otra parte, creo que hubiera requerido un testimonio más personal, el «yo» testigo que se impone especialmente durante la segunda mitad del siglo xx. Serra parece vislumbrar ese «yo», pero no lo desarrolla. En La república posible, aprovecha el uso de nuevas categorías, como «diferencias étnicas», donde desaparece el «yo» testigo y se regresa, por la vía de una jerga más o menos científica, a diferencias abstractas, que no dejan de ser justas pero que carecen del impacto necesario del drama personal de quien ha sido

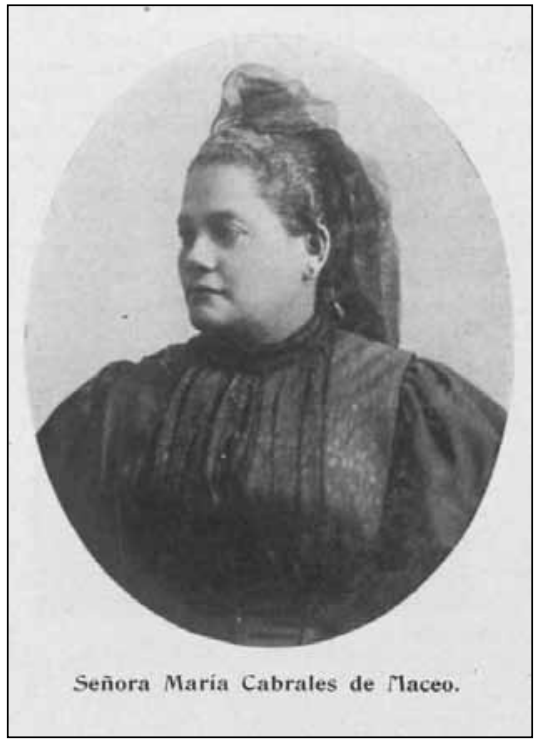

María Cabrales de Maceo. Schomburg Center for Research in Black Culture. The New York Public Library Digital Collections. 1899. objeto del prejuicio y la exclusión no por causa de «diferencias étnicas» sino porque es negro. Por eso es tan sugerente, y conmovedor, el uso fugaz del «yo» en un poema de Serra titulado «A Cuba».

En 1885, después de haber participado en el fallido plan Gómez-Maceo, Serra se refugió en Jamaica, donde publicó un poema titulado "A Cuba», dedicado a María Cabrales, la esposa de Antonio $\mathrm{Maceo}^{4}$. En el poema, compuesto de cuartetos endecasílabos con una rima consonante muy lograda, aunque hoy resulta monótona, se destacan los detalles del proyecto político de Serra, ya plenamente articulados, junto a la irrupción de un "yo» lírico, testigo de las injusticas del sistema colonial, un «yo» testigo cuya presencia no es frecuente en la obra ensayística del cubano ${ }^{5}$. Sobre la suerte del africano en Cuba dice el poema: "Aniquilado el indio jeneroso,/ Rebuscaba otra víctima el tirano/ Y cual hiena, terrible, sanguinoso/ Cebóse, sobre el mísero africano» (4). «Devuélvele á mi raza su prestigio/ Y á mi patria las joyas que arrancaste/ Con la muerte de Plácido y Zenea» (énfasis en el original, 17), dice hacia el final del poema. Llama la atención la frase sobre "el prestigio» de «mi raza»; se trata no solo del derecho sino del poder, incluso de la magia, praestigium, de una raza. Y junto a estos versos, donde irrumpe, una sola vez, un «yo» lírico, dice: "Yo era niño; muy tierno todavía./ Y recuerdo haber visto con frecuencia./ Ejercer su rigor la tiranía,/ Su impunidad, su orgullo, su vioSobre el fracaso del plan Gó mez-Maceo y las actividades independentistas en que participó Serra en estos años, ver Deschamps. Ver también Foner, especialmente el capítulo 8, «Revolutionary Activity 18831887», 112-32.

5 Habría que repasar el epistolario de Serra, que no he podido consultar, para poder apreciar el uso de la primera persona en sus cartas.

La raza y el racismo en la república imposible de Rafael Serra

OSCAR MONTERO 


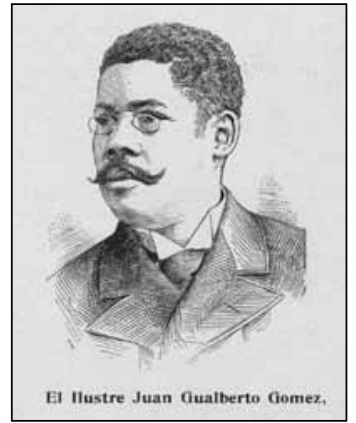

Juan Gualberto Gómez. Schom burg, Center for Research in Black Culture. The New York Public Library Digital Collections. 1899.

Sobre las intervenciones de los Estados Unidos en Cuba durante los años de la Enmienda Platt, ver Pérez.

Sobre la afirmación de Serra y otros que su participación en las luchas independentistas debían garantizar su participación cabal en la fundación de la república, ver Ferrer 135.

Se refiere respectivamente a José Miguel Gómez, presidente de Cuba por el Partido Liberal 1909-1913, que ordenaría la persecución y la matanza de los Independientes de Color en 1912; a Rafael Montoro, o Marqués de Montoro, fundador del Partido Autonomista; a Alfredo Zayas y Alfonso, presidente del Senado en 1906, luego vice-presidente y presidente de la república.

9

Sobre la discriminación en la educación y en otras instituciones públicas y privadas, ver De la Fuente.

10

Argelio Santiesteban, El habla popular cubana de hoy.

La raza y el racismo en la república imposible de Rafael Serra

OSCAR MONTERO lencia» (5). ¿Qué habrá visto ese niño negro en la Cuba colonial? ¿Qué habrá sufrido en su propio cuerpo? son las preguntas que sugiere ese «yo», pero que nos deja con un hipérbaton libresco: «Ejercer su rigor la tiranía». Los versos sugieren otra manera de presentar las injusticias del régimen colonial, pero Serra no sigue por esta ruta. En su prosa, a pesar del poder que puede alcanzar su denuncia, Serra se cuida de no hacerla personal, de no quejarse, de no mostrarse orgulloso, tal vez porque considere que la subjetividad y la queja no son viriles, o porque no considerara la autorepresentación como una táctica eficaz.

Frente a la amenaza constante de la intervención de los Estados Unidos, que manipulaba la política interior de Cuba descaradamente $^{6}$, Serra combate cualquier versión del anexionismo, pero también reconoce la necesidad de enfrentar el poderío del «Coloso del Norte» de manera que favoreciera a todos los cubanos, en particular a los cubanos de origen africano, que lucharon por la independencia y que como él mismo, habían mantenido un perfil destacado durante los años formativos de la república neocolonial. El punto recurrente en los argumentos de Serra es que el negro cubano no tiene que mendigar sus derechos; le pertenecen porque se destacó en la lucha contra el colonialismo español y porque continúa contribuyendo a la nación en diversos frentes ${ }^{7}$.

La evolución que se observa en el pensamiento de Serra va desde la denuncia elocuente del racismo hasta la afirmación de que ningún partido vigente, a pesar de la retórica conciliadora que casi todos predican, tiene el menor interés en mejorar la situación del negro en Cuba. Al contrario, todos los partidos se esforzaban por asegurar la marginación radical de la población de origen africano, permitiendo cuando les fuera conveniente que algunos individuos, bien por sus dotes o porque se acomodaran dócilmente a las demandas del partido que fuera, entraran en sus rangos y prosperaran relativamente. En 1902, recién fundada la república, el Comité de Veteranos y de Sociedades de la Raza de Color organizó un mitin en el Teatro Albizu para «defender los derechos de los veteranos negros y combatir la discriminación» (Fernández Robaina 39). Al igual que Serra, los participantes en dicho mitin, a pesar de su denuncia del racismo, mantuvieron firme la idea de la unión armoniosa entre blancos y negros para lograr la justicia deseada. Juan Gualberto Gómez, dice Fernández Robaina, el orador más aclamado de la reunión, «se había declarado desde la época del Directorio como amante de la unión de blancos y negros». Gómez se había autodenominado el «hombre de la concordia» (43).

En La república posible Serra despliega por última vez el poder de su denuncia. En Cuba, dice Serra, las diferencias entre los partidos es parte de una farsa armada en gran medida por políticos blancos atentos a su bolsillo y a los guiños del Norte que mejor lo rellenaran. Liberales y conservadores, todos, dice Serra, pertenecen a «esa política campanuda, de alejamiento del roce popular, de ceremonia excesiva, política teorizante de cátedra y bufete» (7). La «solemne verdad», continúa, es que si las leyes de la república garantizan los derechos de «la clase de color», todas las otras clases, (se entiende que son las clases de todos los blancos), no tienen la menor intención de cumplir con esa ley. A las clases opresoras pertenecen todos, «sin distingos, y salvo de excepciones, conservadores, liberales y hasta anarquistas; pertenecen miguelistas, montoristas y zayistas» (9) $)^{8}$. Serra da ejemplos específicos de esta «injusticia grande»: tabaqueros de color a quienes no se admite en las fábricas de tabaco, niñas negras que no pueden entrar en las escuelas de caridad, taquígrafos, mecanógrafos, «centenares de jóvenes de color salidos del Instituto Nacional, [que] no pueden tener acceso ni en oficinas públicas ni privadas por el delito consabido [ser negros]» (12)9. Los negros se afiliaron al partido liberal, dice Serra, pero nada han conseguido con esto, y remata su diatriba antirracista con un refrán popular: «todos los pájaros comen arroz y el totí lleva la fama» (12). Es poco frecuente en la obra de Serra el uso del humor popular, pero aquí aprovecha el refrán para rematar su argumento con ironía eficaz. En el refrán que cita Serra se escucha el eco de otros dichos populares cubanos: «La culpa de todo la tuvo el totí» o «más negro que un totí» $(334)^{10}$. Estos refranes contienen la consabida dosis de racismo, a veces solapado, otras descarado: el totí, voz de probable etimología africana, es un pajarito muy negro, poco querido en el campo, pues se come las semillas y los granos, y por eso resulta ser culpable de este y otros males. Serra aprovecha la metonimia vulgar 
del refrán, que vincula el color negro con la maldad, para rematar eficazmente la línea central de su denuncia antirracista: en Cuba al negro le echan la culpa de todo.

Lo peor del caso, continúa Serra, es que en Cuba incluso la injusticia se presta a la burla ajena. «Y dado el triste sistema de choteo que en esta tierra se ha hecho endémico, tal vez mueva a la risa esta verdad [la injusticia del racismo]» (5), dice Serra, anticipándose par de décadas al célebre libro de Jorge Mañach, Indagación del choteo, publicado en 1928. Serra prefigura lo que hoy en día llamaríamos una «crítica cultural», puesto que sugiere que no solo se trata de cambiar un sistema político, cuyas diversas banderas cubren la misma hipocresía racista, el mismo cinismo, sino de cambiar el giro de toda una cultura, aplastada por el fracaso de sus ideales, por la corrupción más descarada y la amenaza constante del vecino voraz. A lo largo de la obra de Serra, culminando en los artículos de La república posible, su libro póstumo, se perfilan los rasgos de un método o métodos que habría que seguir para remediar la situación, para alterar no solamente el sistema sino el corazón de la gente y garantizar algo de ese «equilibrio armónico» deseado e imprescindible para el progreso de todos. Serra sugiere que se trata de crear métodos y estrategias originales, pero no alcanza a definirlos cabalmente antes de su muerte en 1909. No creo que Serra lograra definir con precisión esos métodos necesarios ni alcanzara a promover estrategias que los impulsaran a la meta deseada. Sin embargo, para mejor entender y apreciar los logros y las contradicciones de su esfuerzo, conviene repasar algunas de sus sugerencias para combatir el racismo, sus puntos de apoyo teóricos y sus comentarios sobre la situación de los africano-americanos en los Estados Unidos.

En una nota titulada «La brasa a su sardina», incluida en Para blanco y negros (1907), Serra se refiere a la situación en el Sur de los Estados Unidos, donde el partido demócrata, a pesar de que a los africano-americanos se les ha otorgado el sufragio, insiste en marginarlos «con el fin reprobable de sostener con todos sus horrores esa lepra social [el racismo]». En los estados del Sur, continúa, «Ora se le excluye de todas partes ó se le 'lyncha'; ora se le prohíbe contraer matrimonio con gente de otra raza» y así se excita «el odio y el rencor» (19). Sin embargo, en este y otros artículos, Serra reconoce los avances logrados por los africano-americanos en los Estados Unidos y para respaldar su argumento ofrece estadísticas que prueban la realidad de dichos avances: porcentaje de graduados profesionales, número de personas que ocupan puestos destacados, ingresos, etc. En cambio en Cuba, puntualiza, en otro artículo de Para blancos y negros:

Desgraciados de los negros cubanos, si todo lo que tienen que alcanzar como justa remuneración de sus sacrificios por la independencia y la libertad de Cuba, es el oír cantar el Himno Bayamés, y la adoración ficticia, consagrada á la memoria de nuestros mártires ilustres. Nó, hermanos míos, nosotros merecemos justicia, y no debemos por más tiempo seguir alentando un patriotismo humillante y ridículo. (92)

Es patente la impaciencia de Serra, incluso con los rituales de la memoria, en los cuales el mismo se ha destacado. Por otra parte, en los Estados Unidos, aunque continúen el racismo y sus injusticias, afirma Serra, hay que admirar los avances en los derechos civiles de los ciudadanos africano-americanos, avances que no se manifiestan y que se postergan de la manera más hipócrita en Cuba. Como caso ejemplar en el desarrollo de los derechos civiles en los Estados Unidos, Serra se detiene en Booker T. Washington, especialmente en la creación del Tuskegee Institute, fundado por Washington en 1888.

En un artículo titulado «Promesa cumplida», Serra dice que la fundación del Tuskegee Institute se debe «á la buena moral y á la filantropía constante y real de los blancos americanos, que sin excusa de intereses encontrados de partidos, todos á una, contribuyen al bien de los más necesitados» (Para blancos y negros 144). La persecución de los negros en el Sur de los Estados Unidos se debe más que nada, continúa Serra, a que estos no dan su voto al Partido Demócrata. La realidad, dice, es que «todos, o la mayor parte de los blancos del Sud [sic], ayudan generosamente á Booker T. Washington»: incluso el presidente McKinley y el expresidente Cleveland han contribuido generosamente al proyecto de Washington. Serra concluye su elogio de Washington y del Instituto Tuskegee con una pregunta retórica cuya respuesta es evidente: « ¿Se ayuda, ó no, á los negros en los Estados Unidos?» (144). «El pelear con el más fuerte es locura», Serra cita de Washington, y por lo tanto la única vía para contrarrestar el racismo es la educación

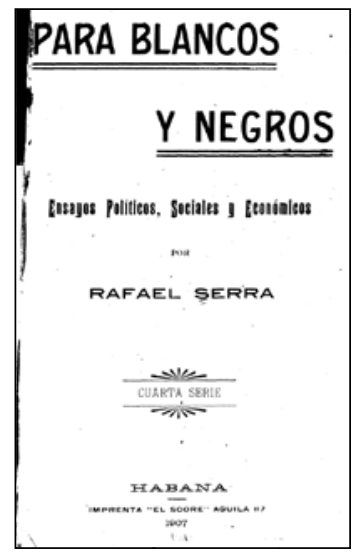

La raza y el racismo en la república
imposible de Rafael Serra OSCAR MONTERO 


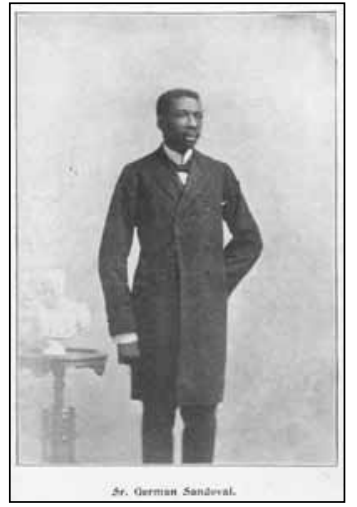

German Sandoval. Primer Presidente de La Liga. Schomburg Center for Research in Black Culture. The New York Public Library Digital Collections. 1899.

11

En los Estados Unidos la célebre organización para "el avance de la gente de color», the National Association for the Advancement of Colored People - NAACP se fundó en febrero de 1909. Entre sus fundadores se destaca W.E.B. Du Bois, autor del ensayo pionero The Souls of Black Folk, publicado en 1903. La prohibición de asociaciones similares en Cuba es notoria, sobre todo la Ley Morúa, que prohibió el Partido Independiente de Color y en gran medida provocó la «Guerra del 12». Sobre la Ley Morúa, su origen y sus consecuencias, ver por ejemplo Helg, De la Fuente, Fernández Robaina, y Pérez, respectivamente.

12

Sobre Estenoz y el Partido Independiente de Color, ver Fernández Robaina 23-103.

13

Además de los estudios ya citados, sobre la «Guerra del 12» ver también «The 1912 Massacre of Afro-Cubans» en http://www.afrocubaweb.com/ history/eldoce.htm

14

El tema de la renovación subjetiva necesaria para combatir el racismo, internalizado y normalizado por sus propias víctimas, es ampliado en otra obra fundadora, Peau noir masques blancs de Fanon, publicada en 1952

La raza y el racismo en la república imposible de Rafael Serra

OSCAR MONTERO y la entrada en un sistema controlado por los blancos, a cuya simpatía y buena voluntad hay que apelar. Serra sugiere que en Cuba un proyecto semejante al de Washington sería un primer paso en la lucha por los derechos civiles. En Cuba bajo el pretexto falso de una unidad nacional ya lograda, pero en realidad inexistente, se rechazaría como innecesaria, perjudicial e incluso ilegal la fundación de instituciones docentes diseñadas específicamente, como el Tuskegee Institute, y como La Liga por cierto, para el «avance de la gente de color» ${ }^{11}$.

No solo en su elogio de Washington sino también en varios artículos incluidos en Para blancos y negros, Serra considera que el avance de «la clase de color» cubana depende de la educación, del esfuerzo de cada uno, de la rectitud moral, incluso de la apariencia, que debe ser sobria, modesta, elegante, como la de señores y señoras decentes. En nada disminuye el valor de la denuncia antirracista de Serra reconocer que su programa para avanzar los derechos del negro es incuestionablemente conservador y que coincide con las ideas de integración pacífica de Booker T. Washington. En un artículo titulado «Roosevelt y los negros», Serra traduce una carta del presidente Theodore Roosevelt a la Liga Nacional de Comerciantes de color, que se reunió en Oyster Bay, New York, en 1905. Dice en parte la carta de Roosevelt, traducida por Serra: «la educación y el dinero, que son el secreto de la superioridad desde que dejara de serlo la fuerza bruta de Hércules, es el punto objetivo y único del negro americano para la solución práctica y decisiva de su complicado problema» (163). Es evidente que Serra busca una «solución práctica» semejante a la que propone Roosevelt para «el problema de los negros» en Cuba; también está claro que hasta sus últimos escritos dicha solución tiene que ser pacífica porque de no serlo sería suicida.

En La república posible, en un artículo fechado en octubre, 1909, la fecha de su muerte, Serra elogia el periódico Previsión, «que dirige nuestro distinguido amigo señor Evaristo Estenoz», fundador del Partido Independiente de Color $^{12}$. Serra añade que gracias a la reaparición del periódico, «deducimos que los chispazos aislados son siempre precursores de algo grande y concreto» (14). Pero a pesar de su simpatía por el proyecto de su amigo y colaborador a Serra le inquietaba toda noción de separatismo militante; lo más probable es que hubiera rechazado cualquier opción que provocara un enfrentamiento violento entre blancos y negros, precisamente lo que ocurrió en la llamada «guerra del 12», liderada por Estenoz, que tampoco alcanzó a ver «algo grande y concreto». La fotografía del cadáver desnudo de Estenoz, rodeado de militares blancos, se puede ver en la red $^{13}$.

En las obras de Serra que he consultado, no encuentro mención de la lectura demoledora que del proyecto de Washington hizo W.E.B. Du Bois en The Souls of Black Folk, publicado en 1903. Du Bois señala los aspectos positivos de dicho proyecto y el deseo sincero de Washington de promover, en circunstancias poco favorables, la educación y el progreso de la gente de color en los Estados Unidos. Sin embargo, en su análisis fundador, brillante e influyente, Du Bois concluye: «Mr. Washington's programme practically accepts the alleged inferiority of the Negro races» «El programa de Washington en efecto acepta la supuesta inferioridad de las razas negras» (15). Du Bois sugiere que para la víctima del racismo, esa noción de inferioridad llega a formar parte de su constitución psicológica y que solo una renovación subjetiva radical puede vencerla $a^{14}$. Sin ese paso, sin esa transformación vital, los proyectos culturales y las reformas políticas jamás lograrían la liberación verdadera del individuo oprimido. Serra no deja de repetir su defensa de la igualdad y del derecho de todos en el plano de la política. Pero era necesario ampliar esa defensa en un plano social y cultural para batallar eficazmente en contra de un sistema racista que funcionaba como si estuviera respaldado por la ley natural. Llevar la defensa de los derechos del negro al plano cultural hubiera requerido una nueva noción de identidad, es decir, al menos el germen de una identidad propia, no solo capaz de enfrentar las opresiones de la raza hegemónica sino de prescindir totalmente de ella. Serra no pudo esbozar semejante identidad y por eso resulta conmovedor contemplar la nobleza de su esfuerzo. En sus comentarios sobre «el nuevo libro» de «Juan Tinot» [Jean Finot]», autor de Le prejugé des races, publicado en 1905, Serra se apoya en un texto prestigioso, publicado en París, que pretende combatir el racismo, pero que a la vez mantiene el vigor de las categorías racistas más absurdas. 
Serra elogia uno de los puntos centrales del libro de Finot en una reseña, publicada en Para blancos y negros, cuyo título traduce el título del libro del escritor francés: «El prejuicio de las razas». En su tratado, de más de 500 páginas, Finot alega que hay que rechazar rotundamente toda la pseudociencia de la época que insistía en el carácter innato e inviolable de las diferencias raciales. Por ejemplo, Finot dedica todo un capítulo a un análisis detallado de la «craneología», en aquellos años una rama prestigiosa de la antropología, ocupada en medir el cráneo de los individuos para determinar su nivel de inteligencia, su predisposición al crimen, etc. Finot afirma que la craneología, la antropología, la psicología, la filología constituyen ficciones inventadas por los blancos para presentar como barreras inviolables cualquier diferencia entre las razas:

La science de l'inégalité est par excellence une science des Blancs. Ce sont eux qui l'ont inventée, lancée, soutenue, nourrie et propagée, grâce à leurs observations et à leurs déductions. Se considérant au-dessus des hommes d'autres couleurs, ils ont érigé en qualités supérieures tous les traits qui leur étaient propres, en commençant par la blancheur de leur peau et la souplesse de leurs cheveux. Mais rien ne prouve que leurs traits si vantés soient des traits de supériorité réelle! (490)

La ciencia de la desigualdad es por excelencia una ciencia de blancos. Son ellos los que han inventado, lanzado, sostenido, alimentado y propagado, gracias a sus observaciones y sus deducciones. Al considerarse por encima de los hombres de otros colores, han erigido en cualidades superiores todos los rasgos que les eran propios, comenzando por la blancura de la piel y la docilidad de sus cabellos. ¡Pero nada prueba que estos rasgos tan exaltados sean rasgos de superioridad real!

Finot rechaza las categorías racistas de las pseudo-ciencias de la época, y Serra encuentra en ese rechazo una justificación casi científica de la igualdad innata de todos los seres humanos, igualdad que debe entonces garantizar sus derechos como ciudadanos. Pero si se detiene uno en este comentario, característico de la lógica del libro de Finot, es evidente que si estos "rasgos» físicos no constituyen una «superioridad real», tampoco se cuestiona en lo absoluto la superioridad del pelo lacio y «dócil», por ejemplo, sobre el cabello negro y muy crespo. Finot repite una y otra vez que todos estos rasgos dependen del medio ambiente y que por lo tanto pueden tornarse en rasgos más favorables, es decir, en rasgos que pueden acercar a un individuo de cualquier raza a las características de los europeos.

Hoy día las conclusiones de Finot nos pueden parecer irrisorias pero finalmente resultan grotescas y perturbadoras, sobre todo porque Finot, que se presenta como paradigma de objetividad científica, no quiere o no puede percatarse en lo absoluto del racismo medular y tóxico de todo su libro. Dicho racismo es particularmente repugnante cuando habla del "progreso» del africano-americano en los Estados Unidos. En pocos años, dice Finot, los rasgos biológicos del africanoamericano lo distancian de «sus hermanos africanos». Incluso en una raza de rasgos tan «pronunciados» [la raza de los africanos], la influencia del medio, el caballo de batalla de Finot, es capaz de alterar características físicas, intelectuales y morales.

Dice Finot sobre los africano-americanos y sus antepasados africanos:

Mais suivons leur évolution aux Etats-Unis, et nous verrons comment, exposé à l'action des facteurs qui ont forgé $\mathrm{l}^{\prime}$ âme des Blancs, ce même Nègre stupide, insouciant, souvent même anthropophage, s'approprie la mentalité et les conceptions intellectuelles de ces derniers. (457).

Sigamos su evolución en los Estados Unidos, y veremos cómo, expuestos a la acción de factores que han forjado el alma de los Blancos, este mismo Negro estúpido, despreocupado y vago, incluso antropófago, se apropia de la mentalidad y las concepciones intelectuales de estos últimos [de los blancos].

Concluye Finot, «leur progrès intellectuels et moraux, acommplis pendant un laps de temps aussi court, démonstrent que toutes les races humaines sont capables de s'élever au niveau des Blancs» «[el] progreso intelectual y moral [de los africano-americanos] obtenido en tan poco tiempo, demuestra que todas las razas humanas son capaces de elevarse al nivel de los Blancos» (482). No vale la pena detenerse en los comentarios absurdos de Finot sobre la gran belleza de las «cuarteronas» $\mathrm{y}$ «octavonas», los términos que emplea, del Instituto Tuskegee, mujeres de «tinte de ámbar», «de perfil fino y casi altivo», ca-

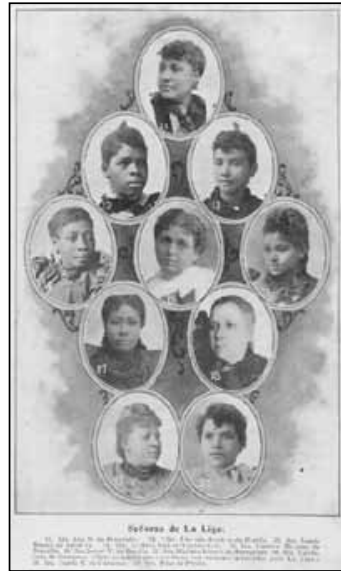

Mujeres de La Liga. Schomburg Center for Research in Black Culture. The New York Public Library Digital Collections. 1899.

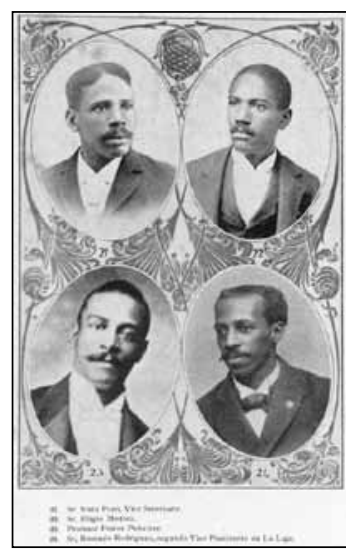

Miembros de La Liga. Schomburg Center for Research in Black Culture. The New York Public Library Digital Collections. 1899.

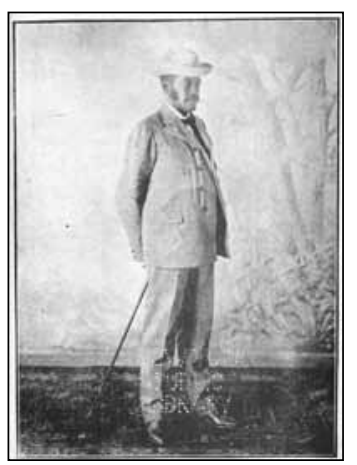

Rafel Serra. Schomburg Center for Research in Black Culture. The New York Public Library Digital Collections. 1907.

La raza y el racismo en la república imposible de Rafael Serra

OSCAR MONTERO 
paces de seducir a cualquier europeo (453). De la denuncia contra la falsedad científica de categorías raciales, y racistas, Finot pasa, sin el menor titubeo, a otro plano, donde la superioridad estética y moral de los europeos se da por sentada.

En Para blancos y negros, después de los comentarios de Serra sobre el libro de Finot, sigue un artículo breve de Ursula Coimba de Valverde, pianista y escritora elogiada por Serra en una nota junto a la foto de la «distinguida pianista, hábil maestra de música y escritora de pluma colorida y fácil» (100). Coimba de Valverde cita un comentario de José María de Céspedes, periodista de la época, que hace eco de los comentarios del francés Finot: «No hay más que un medio seguro para borrar las diferencias: que las razas inferiores se eleven hasta las superiores, por medio de la educación y la instrucción. La inteligencia es el gran nivelador de la especie humana» (101).

No se puede argüir que las categorías expuestas por Finot, y respaldadas por Serra, fueran el orden del día a principios del siglo pasado. Los comentarios de Du Bois contra el proyecto de Washington, publicados como ya mencioné en 1903, ofrecen un punto de vista absolutamente opuesto, es decir un ataque no solo al racismo sino a cualquier manera de pensar y a cualquier escala de valores que lo respaldaran, aunque fuera inconscientemente. En la reseña del libro de Finot en su traducción al inglés, Race Prejudice, publicada en 1925, el autor se percata perfectamente de los prejuicios no de las razas sino de Finot. El antropólogo T.T. Waterman, que reseña el libro, dice «[Finot] believes that "race" prejudice with all its fruits is intellectually foolish and morally wrong, but in the very first page of his "Foreword," he commits himself to the idea that civilization is "Anglo-French humanity," nothing more» "[Finot] cree que el prejuicio "racial" con todos sus frutos es una tontería, desde un punto de vista intelectual, y falso, desde un punto de vista moral; sin embargo, en la primera página de su "Prólogo," se compromete a la idea que la civilización es “anglo-francesa” y nada más» (152).

En la preparación para la guerra de independencia, el valor del célebre llamado de Martí a la unidad de todos para obtener un bien común es incuestionable. Incuestionable también es el valor del esfuerzo incansable de Serra para mantener viva la prédica martiana de la igualdad en el ambiente tóxico de la república mediatizada. Es loable el gesto fundador de Serra en la lucha por los derechos civiles de todos, pero para entender cabalmente su papel y la importancia de su legado hay que reconocer las ambigüedades y las paradojas de su posición frente a la raza y el racismo. Es cierto, como lo ha sugerido Cabrera Peña, que en la obra de Serra se perfilan los rasgos de una alternativa pacífica para combatir los horrores del racismo e iniciar un proyecto que podría dar fruto en años venideros. «Serra se ha abierto», dice Cabrera Peña, «antes de publicar La república posible, a los vislumbres de la resistencia pacífica» (29). La resistencia pacífica, impulsada por Gandhi, pudo haber sido una vía intermedia entre la militancia de Evaristo Estenoz y el evangelio unificador martiano, ineficaz en la república neocolonial. Creo que un punto de partida de ese camino pudo haber sido el testimonio personal de Serra, origen de una identidad posible, autóctona, totalmente independiente tanto del odio como de la buena voluntad de los blancos. Si Serra no alcanzó a vislumbrar semejante autonomía, no se trata de juzgarlo desde la perspectiva del siglo XXI, pero sí reconocerlo, a pesar de los límites de su propuesta antirracista, como precursor de lo que se pueda hacer hoy y de lo que mucho que hay por hacer.

Las numerosas fotografías incluidas en la obra de Serra muestran señores y señoras blancos y negros endomingados debidamente, mujeres de cuello alto y corset, hombres elegantes, de solapa y corbatín, como si el propósito de este álbum de la familia cubana fuera mostrar la capacidad de todos, blancos y negros, de lucir bien. Sin duda, era el estilo del retrato en aquellos años, pero la técnica ya existía para producir otro tipo de imagen, la imagen de un obrero por ejemplo o de un campesino, o del cadáver de Estenoz. El proyecto de afirmación de los derechos civiles en los Estados Unidos ocupó el sudor, la sangre y las energías de generaciones a lo largo del siglo pasado. Ese proyecto no dependió de la buena voluntad de los blancos sino de la lucha de miles de personas en diversos frentes culturales, en las manifestaciones masivas, en el horror de las ciudades incendiadas, en el liderato de Martin Luther King, Jr. En cambio, en Cuba, de la república mediatizada pasamos a 
la república imposible. La violencia que temía Serra culminó en la masacre de Estenoz y los líderes del Partido Independentista y sirvió para legitimar el odio entre las razas.

En el panfleto titulado Negros contra Blancos en Cuba, publicado en 1912, los autores Rafael Conte y José Campany condenan a los sublevados, tildados de «racistas» $\mathrm{y}$ «cobardes», y alaban la eficacia de los artilleros del ejército cubano, entrenados, dicen los autores con orgullo, por oficiales norteamericanos. Concluyen los autores, periodistas testigos de la contienda:

No hay que hacerse ilusiones sobre este punto: las dos razas que pueblan la República de Cuba se han declarado recíprocamente la guerra, han venido á las manos, han hecho correr la sangre; y de hoy más, el profundo recelo de los blancos servirá de contrapeso al odio inextinguible de los negros. (7)

En la república imposible, la unidad martiana, su célebre "no hay razas», se convirtió en un lema vacío, aprovechado a lo largo del siglo pasado por los políticos de turno de la manera más cínica, en una retórica tan hueca como persistente. Sin embargo, sobre todo por la ruta de las artes, se exploraron opciones a lo largo del siglo pasado para combatir el racismo frente al fracaso de instituciones políticas y culturales que pretendieron remediarlo. En un artículo publicado en Afrocubaweb, diciembre 4, 2012, el escritor y activista Roberto Zurbano dice, «Un pensamiento negro se ha configurado a través de todo el siglo XX cubano, pero ha hecho su verdadera explosión en las puertas del siglo XXI, cuando se mezclan nombres, temas, libros y discusiones diversas e intermitentes que ahora vienen a alimentar las necesarias estrategias de acción social» ${ }^{15}$.

Para blancos y negros incluye un artículo sobre «El Rockerfeller Negro», un tal Mr. P.J. Groves, prototipo admirado por Serra del self-made man, de quien dice: «Mr. Groves, viste, habla y actúa de manera tal, que si se le pusiese una careta, sería tomado por cualquier blanco cultamente educado. De modo que puede decirse que su caballerosidad es innata» (167). Serra se mantuvo fiel a la idea de esa «caballerosidad innata», pero también se cuidó de vestirse y de actuar como "cualquier blanco educado». Su credo martiano de igualdad para todos, fielmente atesorado durante toda su labor antirracista, no le permitió abandonar su fe en ese valor interno, pero Serra no pudo o no quiso aceptar que para el opresor blanco ese interior carecía de valor puesto que en un individuo de piel oscura y pelo crespo no veía ni un caballero ni un campesino ni un pordiosero, solo «un negro». Merece Serra no solo que se lea y relea su obra sino que se publique en ediciones accesibles que permitan evaluar su legado, apreciar sus logros y sus límites. Merece que su labor y su obra se lean no como artefactos de una época horrenda de nuestra historia, remota y superada, sino como un texto capaz de dialogar con nuestros propios prejuicios, capaz de hacerlos más visibles y por eso más vulnerables.

\section{Bibliografía}

Cabrera Peña, Miguel. «Alma Fundadora. Rafael Serra y Montalvo». Islas 3.9 (mayo 2008): 21-33.

Conte, Rafael. Guerra de razas: negros contra blancos en Cuba. La Habana: Imp. Militar de Antonio Pérez, 1912.

Deschamps Chapeaux, Pedro. Rafael Serra y Montalvo, obrero incansable de nuestra independencia. La Habana: Unión de Escritores y Artistas de Cuba, 1975.

$\mathrm{Du}$ Bois, W.E.B. The Souls of Black Folk. 1903. New York: Barnes \& Noble Classics, 2005.

Fanon, Frantz. Peau noire, masques blancs. Paris: Éditions du Seuil, 1952.

Fernández Robaina, Tomás. El negro en Cuba 1902-1958. La Habana: Editorial de Ciencias Sociales, 1990.

Ferrer, Ada. Insurgent Cuba. Race, Nation, and Revolution, 1868-1898. Chapel Hill, N.C.: The University of North Carolina Press, 1999.

Finot, Jean. Le préjugé des races. 4ta ed. Paris: Librairie Félix Alcan, 1921. http://archive. org/details/leprjugdesra0ofinouoft

Foner, Philip S. Antonio Maceo. The "Bronze Titan" of Cuba's Struggle for Independence. New York and London: Monthly Review Press, 1977.

Fuente, Alejandro de la. A Nation for All. Race, Inequality, and Politics in Twentieth-Century Cuba. Chapel Hill, N.C.: University of North Carolina Press, 2001.
15

Conocí a Roberto Zurbano en Manhattan College, ciudad de New York, donde dio una charla en noviembre, 2012, sobre la raza y el racismo en Cuba. Poco tiempo después de entregado mi artículo al editor de este número especial de América Sin Nombre, la traducción de un artículo de Zurbano en el New York Times ha desatado una polémica importante sobre la raza y el racismo en Cuba. 
González, Veranes P. N. La personalidad de Rafael Serra y sus relaciones con Martí. La Habana: Imprenta «La Verónica», 1943.

Helg, Aline. Our Rightful Share. The AfroCuban Struggle for Equality 1886-1912. Chapel Hill, N.C.: University of North Carolina Press, 1995.

Mañach, Jorge. Indagación del choteo. La Habana: Revista de Avance, 1928.

«The 1912 Massacre of Afro-Cubans». http:// www.afrocubaweb.com/history/eldoce.htm

Pérez, Louis A. Cuba under the Platt Amendment, 1902-1934. Pittsburgh, Pa: University of Pittsburgh Press, 1986.

Santiesteban, Argelio. El habla popular cubana de hoy. La Habana: Editorial de Ciencias Sociales, 1982.

Serra, Rafael. Ecos del alma. Ensayo literario. Kingston, Jamaica: DeSouza, 1885.

- Ensayos políticos. Segunda serie. New York: Imprenta de P.J. Díaz, 1896.

- Ensayos políticos, sociales y económicos. Tercera serie. New York: Imprenta de A.W. Howes, 1899. Incluye la mayor parte de los editoriales y otros artículos publicados en el periódico La Doctrina de Martí, Nueva York (1896-1898) y La Habana (1899-1901).

- Para blancos y negros: ensayos políticos, sociales, económicos. Habana: Imprenta «El Score», 1907.

- La república posible. Habana: Imprenta de Rambla y Bauza, 1909.

Waterman, T.T. Reseña de Race Prejudice de Jean Finot.. Traducción de Florence Wade-Evans. New York: E. P. Dutton and Co., 1924. American Anthropology 27.1 (Jan.-March 1925): 151-153. http:// onlinelibrary.wiley.com/doi/10.1525/ aa.1925.27.1.02a00130/pdf

Zurbano Torres, Roberto. «Un grito de alerta para el siglo XXI». Reseña de 1912. Voces para un silencio. http://www.afrocubaweb. com/grito-de-alerta.pdf

Fecha de recepción: 09/03/2014

Fecha de aceptación: 07/10/2014

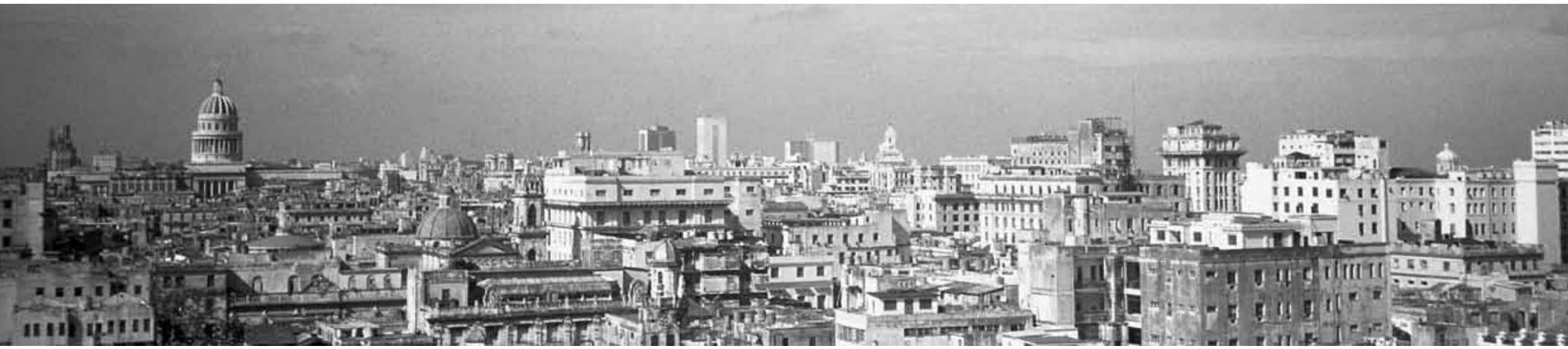

La Habana. Fotografía de José Gomariz. 